J. Amer. Soc. Hort. Sci. 116(5):894-898. 1991.

\title{
Genetic Variation for Objective and Subjective Measures of Fresh Fruit Color in Strawberries
}

\author{
Douglas v. Shaw \\ Department of Pomology, University of California, Davis, CA, 95616 \\ Additional index words. Fragaria $\times$ ananassa, heritability, genetic correlation, genotype $\times$ environment interaction
}

\begin{abstract}
The heritabilities of, and genetic correlations among, variables that describe internal and external color in fresh strawberry (Fragaria $\times$ anarrassa) fruit were estimated using factorial analyses of seedlings from 20 controlled crosses. Hunter $L$ and a values, and a subjective score generated by comparison with color plates were obtained for seedling genotypes and their parents at two locations. Genetic effects were responsible for 33\% to $61 \%$ of the phenotypic variance for color traits, after correction for location effects. Means for objective color variables differed significantly between locations, but means for subjective color scores did not. Genetic $\times$ location interaction variances were usually nonsignificant, and were $<12 \%$ of the phenotypic variance for all variables. Phenotypic and genetic correlations between objective and subjective color scores were significant and large (absolute values of $r=0.42-$ $\left.0.69 ; r_{g}=0.84-1.00\right)$. Multiple regression of subjective scores on $L$ and a explained $69 \%$ and $59 \%$ of the phenotypic variation for external and internal color, respectively. Genetic correlations between measures of internal and external color were small and mostly nonsignificant, suggesting that separate sets of genes condition these traits.
\end{abstract}

Color is the first quality factor of strawberries perceived by the consumer. The failure of a cultivar to produce fruit with acceptable color will limit its usefulness, regardless of other positive attributes it may possess. Developing cultivars with color qualities that satisfy specific consumer needs depends on the expression of genes that condition color in relevant selection and production environments.

Genotypic differences for color intensity and stability have been studied extensively in processed and frozen strawberry fruit products (Hoover and Dennison, 1954; Morris et al., 1985; Sistrunk and Morris, 1985; Wrolstad et al., 1970), but little information is available regarding genetic variation for color traits in fresh fruit. Lundergan and Moore (1975) demonstrated substantial heritable variation for the color of strawberry juice extracted from fresh fruit, using seedlings from crosses among parents selected for divergent and intermediate color phenotypes. They estimated a broad-sense heritability of 0.81 for juice color, and inferred partial dominance for dark color by comparing progeny means with parental values.

Color in fresh strawberry fruit is conditioned in part by postharvest treatments that affect respiration and enzymatic browning (Gross, 1987; Rosen and Kader, 1989; Sistrunk and Morris, 1985), and the consequences of specific treatments may differ depending on the tissue or product evaluated. For example, controlled atmospheres with elevated levels of $\mathrm{CO}_{2}$ retarded flesh color development but had no effect on skin or juice color for fresh strawberries stored at $0 \mathrm{C}$ ( $\mathrm{Li}$ and Kader, 1989). Preharvest environmental variables such as light, temperature, and nutritional factors affect the synthesis of anthocyanin and the development of fresh fruit color (Gross, 1987). However, I found no reports quantifying the effect of differing production environments on the development of strawberry fruit color and the interactions of genetic and environmental factors in color expression.

The distribution of color within strawberry fruit can differ substantially among cultivars (Sistrunk and Morris, 1985). Patterns of color distribution have been related to the localization and quantity of anthocyanin pigments in different tissues for

Received for publication 22 Oct. 1990. The cost of publishing this paper was defrayed in part by the payment of page charges. Under postal regulations, this paper therefore must be hereby marked advertisement solely to indicate this fact. several fruit species (Gross, 1987). In strawberry fruit, anthocyanin is found in the epidermis, cortex, and pith (Gross, 1987). Genetic independence of internal and external color may result if anthocyanin is synthesized or partitioned differently among these tissues. The inheritance of internal color may be further complicated by genetic variation for the relative proportions of each tissue in the edible fruit. Whether internal and external strawberry fruit color are conditioned by identical or distinct sets of genes has not been determined.

The following study was conducted to quantify the genetic and environmental parameters for variables that describe color in fresh strawberry fruit, and to determine whether internal and external fruit color are conditioned by similar or distinct sets of genes.

\section{Materials and Methods}

Materials and scoring procedures. Seedlings from 20 biparental crosses among nine parent genotypes and runner plants from the parents were planted in a nursery at the Wolfskill Experimental Orchard near Winters, Calif., in June 1989. These crosses were a sample of those generated in developing new cultivars, and the parents were a representative sample of the current advanced-generation germplasm available within the Univ. of California cultivar improvement program. Runners from each parent and from 20 unselected seedlings per cross were harvested on 27 Oct., stored at $2 \mathrm{C}$, and planted at Winters and at the Univ. of California Strawberry Research Facility near Watsonville, Calif., on 8 and 9 Nov., respectively. The 20 seedling genotypes from each cross were represented at both locations by a single runner plant; trials were established with two completely random plots of 10 genotypes per cross at each location. Parental genotypes were represented by a single plot of 10 runners at each location. All plants were cultured as recommended for winter-planted commercial plantations (Voth and Bringhurst, 1970; Welch, 1989).

Fruit from individual genotypes were harvested on $20 \mathrm{Apr}$. at Winters and 17 May at Watsonville. Sample dates were chosen near the midpoint of the production season for each location. Only fruit with complete surface coloration were collected; damaged or overripe fruit were discarded. Samples were stored at 0C and evaluated for color within 3 days of harvest. $\mathrm{Li}$ (1990) detected no significant changes in either external or juice color (Hunter a value) for fresh strawberry fruit stored at $0 \mathrm{C}$ for 8 
days, and variable storage is expected to have little consequence for my study. Further analyses were conducted using 318 seedling genotypes that produced sufficient fruit for evaluation at both locations.

Internal and external fruit color were evaluated objectively using a Colormet reflectance spectrophotometer (Agtron, Reno, Nev.), with a 1-cm aperture. Reflectance was expressed as Hunter L, a, and b values (Francis, 1969), standardized to a white tile $(\mathrm{L}=100, \mathrm{a}=0, \mathrm{~b}=0)$. External $\mathrm{L}$, $\mathrm{a}$, and $\mathrm{b}$ values for seedling genotypes were assigned as the average for three representative fruit, with two readings (on opposite sides) for each fruit; values for parental genotypes were calculated using 10 representative fruit, with two readings per fruit. Hunter $b$ values were highly correlated with corresponding a values $(r>0.75$, $P<0.01)$ and were not considered in further analyses, as they contain mostly redundant information. Internal $L$ and a values were determined by slicing the fruit used for external color evaluations longitudinally, and immediately reading the core of both sections. For internal measurements, the aperture was placed just inside the epidermis, midway between the calyx and tip ends of the longitudinal slice and, therefore, integrated the color expressed in cortex and pith tissues. Consequently, genetic parameters estimated for internal color reflect variation for pigment concentration in and variation for the relative proportions of pith and cortex tissues.

Internal and external color were evaluated subjectively (by a single observer) by comparing skin or core tissue with standard color plates. Scores were assigned from a two-axis color chart, synthesized using color chips obtained from a Pantone Color Specifier (747XR; Pantone, Moonachie, N.J.). The first axis of this chart included plates with increasing levels of red pigment, and the second axis included plates with constant pigment but increasing gray content. These axes were intended to simulate objective variables, and are labeled $\mathrm{a}^{\prime}$ and $\mathrm{L}^{\prime}$, respectively. Values for a' and $\mathrm{L}^{\prime}$ were assigned from 1 to 8, with higher values indicating greater pigment or gray content. A single combined subjective score was calculated a $\sqrt{\mathrm{L}^{\prime 2}+\mathrm{a}^{\prime 2}}$, or the hypotenuse of the triangle defined by the point ' $\left(\mathrm{L}\right.$ ', $\left.\mathrm{a}^{\prime}\right)$, and the zero-axis for each component variable.

Genetic analyses. The 20 biparental crosses included in the test resulted from a factorial mating design (Comstock and Robinson, 1948), with five female and four male parents. The main effects of females, males, locations, and all possible interactions were tested assuming a random effects model and using analysis of variance (ANOVA) results and Type III expected mean squares provided by SAS Procedure GLM (Table 1). Model components of variance and covariance were estimated by equating linear functions of the expected mean squares given in Table 1 with

Table 1. Form and expected mean squares for factorial ANOVA for six strawberry fruit color variables.

\begin{tabular}{|c|c|c|}
\hline Source & df & $\mathrm{EMS}^{\mathrm{z}}$ \\
\hline Location (L) & 1 & $\sigma^{2}+k_{1} \sigma_{l m f}^{2}+k_{2} \sigma_{1 f}^{2}+k_{3} \sigma_{l m}^{2}+k_{7} \sigma_{1}^{2}$ \\
\hline Males (M) & 3 & $\sigma^{2}+k_{1} \sigma_{l m f}^{2}+k_{3} \sigma_{l m}^{2}+k_{4} \sigma_{m f}^{2}+k_{6} \sigma_{m}^{2}$ \\
\hline Females $(\mathrm{F})$ & 4 & $\sigma^{2}+\mathrm{k}_{1} \sigma_{\mathrm{lmf}}^{2}+\mathrm{k}_{2} \sigma_{\mathrm{lf}}^{2}+\mathrm{k}_{4} \sigma_{\mathrm{mf}}^{2}+\mathrm{k}_{5} \sigma_{\mathrm{f}}^{2}$ \\
\hline $\mathrm{M} \times \mathrm{F}$ & 12 & $\sigma^{2}+k_{1} \sigma_{l m f}^{2}+k_{4} \sigma_{m f}^{2}$ \\
\hline $\mathrm{L} \times \mathrm{M}$ & 3 & $\sigma^{2}+k_{1} \sigma_{\operatorname{lm} f}^{2}+k_{3} \sigma_{l m}^{2}$ \\
\hline $\mathrm{L} \times \mathrm{F}$ & 4 & $\sigma^{2}+k_{1} \sigma_{l m f}^{2}+k_{2} \sigma_{1 f}^{2}$ \\
\hline $\mathrm{L} \times \mathrm{M} \times \mathrm{F}$ & 12 & $\sigma^{2}+\mathrm{k}_{1} \sigma_{\operatorname{lmf}}^{2}$ \\
\hline Within & 596 & $\sigma^{2}$ \\
\hline
\end{tabular}

${ }^{2}$ Coefficients were estimated using SAS Procedure GLM and type III sums of squares as follows: $\mathrm{k}_{1}=15.6, \mathrm{k}_{2}=61.0, \mathrm{k}_{3}=76.1, \mathrm{k}_{4}=$ $31.3, \mathrm{k}_{5}=122.0, \mathrm{k}_{6}=152.3, \mathrm{k}_{7}=152.3$. experimental mean squares or mean cross-products (Searle, 1971). Causal genetic and genetic $\times$ location $(G \times L)$ interaction components of variance and heritabilities were estimated as follows (Hallauer and Miranda, 1981):

$$
\begin{gathered}
\sigma_{\mathrm{a}}^{2}=2\left(\sigma_{\mathrm{f}}^{2}+\sigma_{\mathrm{m}}^{2}\right) \\
\sigma_{\mathrm{d}}^{2}=4\left(\sigma_{\mathrm{fm}}^{2}\right) \\
\sigma_{\mathrm{al}}^{2}=2\left(\sigma_{\mathrm{fl}}^{2}+\sigma_{\mathrm{ml}}^{2}\right) \\
\sigma_{\mathrm{dl}}^{2}=4\left(\sigma_{\mathrm{fm} l}^{2}\right) \\
\sigma_{\mathrm{e}}^{2}=\sigma^{2}-\left[\begin{array}{c}
\sigma_{\mathrm{f}}^{2}+\sigma_{\mathrm{m}}^{2}+3\left(\sigma_{\mathrm{fm}}^{2}\right)+ \\
\left.\sigma_{\mathrm{fl}}^{2}+\sigma_{\mathrm{ml}}^{2}+3\left(\sigma_{\mathrm{fml}}^{2}\right)\right] \\
\mathrm{h}^{2}=\frac{2\left(\sigma_{\mathrm{f}}^{2}+\sigma_{\mathrm{m}}^{2}\right)}{\sigma_{\mathrm{f}}^{2}+\sigma_{\mathrm{m}}^{2}+\sigma_{\mathrm{fm}}^{2}+\sigma_{\mathrm{fl}}^{2}+\sigma_{\mathrm{ml}}^{2}+\sigma_{\mathrm{fml}}^{2}+\sigma^{2}} \\
2\left(\sigma_{\mathrm{f}}^{2}+\sigma_{\mathrm{m}}^{2}\right)+4\left(\sigma_{\mathrm{fm}}^{2}\right)
\end{array}\right.
\end{gathered}
$$

In Eqs. [1]-[7], $\sigma_{\mathrm{a}}^{2}, \sigma_{\mathrm{d}}^{2}, \sigma_{\mathrm{al}}^{2}, \sigma_{\mathrm{dl}}^{2}$, and $\sigma_{\mathrm{e}}^{2}$ are estimates of the additive genetic, dominance genetic, additive $\times$ location, dominance $\times$ location, and error components of variance, respectively; $\mathrm{h}^{2}$ and $\mathrm{H}^{2}$ are individual-plant narrow-sense and broadsense heritabilities, respectively.

Genetic correlations were estimated as (Becker, 1984):

$$
r_{g}=\frac{2\left[\operatorname{Cov}(x y)_{f}+\operatorname{Cov}(x y)_{m}\right]}{\sqrt{\sigma_{a x}^{2}{ }^{*} \sigma_{a y}^{2}}}
$$

in which $\operatorname{Cov}(x y)_{\mathrm{f}}$ and $\operatorname{Cov}(\mathrm{xy})_{\mathrm{m}}$ are components of covariance for traits $\mathrm{x}$ and $\mathrm{y}$ due to female and male sources, and are estimated from expected and experimental mean cross products obtained using the MANOVA option of SAS Procedure GLM (SAS, Institute, Inc., 1985); $\boldsymbol{\sigma}_{\mathrm{ax}}^{2}$ and $\boldsymbol{\sigma}_{\mathrm{ay}}^{2}$ are the additive genetic variances for traits $\mathrm{x}$ and $\mathrm{y}$, respectively, estimated as in Eq. [1].

The assumptions required for valid interpretation of genetic parameter estimates in strawberry have been discussed previously (Comstock et al., 1958; Shaw et al., 1988), but three caveats specific to the present study should be mentioned. First, current California germplasm has been derived through multiple cycles of breeding and selection, and all advanced selections are related to some extent. However, none of the crosses generated here were among parents that shared a recent common ancestor (inbreeding increments less than $\mathrm{F}=0.07$ ). The increments of inbreeding accumulated in each prior generation have been small, and cycles of mating have been alternated with intervening cycles of intensive selection. Empirical studies have failed to detect a relationship between pedigree inbreeding coefficients and cross means (Shaw, 1991), which, together with theoretical treatments of combined inbreeding and selection (Falconer, 1981), suggest that current genetic parameter estimates will be unbiased. Second, individual seedling values for objective variables were assigned using the average of several fruit samples per plant, and error components of variance were estimated on a sample-mean basis. As a result, both error variances and heritabilities would differ for experiments conducted with sampling procedures different from those I used. Third, identical sets of genotpyes were used at both locations rather than random samples of seedlings from the same crosses. Although this procedure facilitates direct between-location comparisons for individual genotypes, it can increase the similarity of family means between locations and bias estimates of genetic 
variances upward. The magnitude of the bias is expected to be small with the progeny sizes used for this study.

\section{Results and Discussion}

The genotypes used as parents for this study had been considered originally as advanced selections with commercial potential, and their values for color variables (Table 2) are characteristic of current commercial cultivars. Items 83.76-1 and 86.65-201 have light external color, and selections with less external color would not be commercially acceptable in California. Individual parent genotypes differed by $4.3 \mathrm{SD}$ for external a value (range: 28.6-37.7, Table 2) and three SD for intenral a value (range: $28.0-38.5$, Table 2), with all other color variables having intermediate ranges of variation.

Significant differences $(P<0.05)$ between offspring and parent populations were not detected for any of the variables used to describe fruit color (Table 3). This result differed from those of Lundergan and Moore (1975), where offspring juice color values were skewed toward the darker parent. External subjective scores were significantly larger than internal scores, and external $\mathrm{L}$ values were significantly smaller than internal $\mathrm{L}$ values, indicating that external color was darker than internal color for Watsonville and Winters populations. However, significant differences were not detected between external and internal a, suggesting that the average color saturation of external and internal tissue was similar.

Significant genetic effects were detected for all color variables (Table 3). Male effects differed significantly for all variables, whereas female effects were significant for all internal color variables (Table 4). Significant male $\mathrm{x}$ female interactions, indicating the presence of dominance variance, were de-

Table 2. Means for six fresh fruit color variables for nine strawberry genotypes used as parents, with values averaged for two test locations. $^{z}$

\begin{tabular}{|c|c|c|c|c|c|c|}
\hline \multirow[b]{2}{*}{ Parent } & \multicolumn{3}{|c|}{ External color } & \multicolumn{3}{|c|}{ Internal color } \\
\hline & $\mathrm{L}$ & $\mathrm{a}$ & Score $^{y}$ & $\mathrm{~L}$ & a & Score' \\
\hline $83.49-1$ & 26.0 & 31.0 & 8.9 & 45.5 & 37.0 & 6.4 \\
\hline $83.76-1$ & 30.0 & 37.0 & 7.1 & 57.5 & 28.0 & 2.9 \\
\hline $83.93-6$ & 27.5 & 32.5 & 8.5 & 42.5 & 38.5 & 6.7 \\
\hline $84.8-1$ & 26.6 & 29.0 & 9.2 & 50.8 & 30.4 & 5.5 \\
\hline $85.19-29$ & 29.9 & 33.2 & 8.4 & 49.3 & 34.4 & 5.3 \\
\hline $85.72-201$ & 28.3 & 28.6 & 8.3 & 46.1 & 36.8 & 6.1 \\
\hline $85.188-201$ & 26.0 & 30.5 & 8.5 & 49.0 & 29.0 & 5.7 \\
\hline $86.65-202$ & 32.2 & 37.7 & 7.4 & 57.2 & 29.9 & 2.9 \\
\hline $86.169-1$ & 27.5 & 32.0 & 8.1 & 49.0 & 38.0 & 5.7 \\
\hline
\end{tabular}

${ }^{2}$ Pooled SD for comparison of parent means are: $1.7,2.1,4.1$, and 3.5 for external Hunter L, a, internal L, a, respectively.

${ }^{y}$ Subjective, based on color chart. tected only for external a and the external subjective score. Additive genetic effects were responsible for $62 \%$ to $100 \%$ of the total genetic variance; dominance variance was small for all variables except for the external subjective $\operatorname{sco}\left(\boldsymbol{\sigma}_{\mathrm{d}}^{2} /\left(\sigma_{\mathrm{a}}^{2}+\sigma_{\mathrm{d}}^{2}\right)\right.$ $=0.38$, Table 5). Narrow-sense heritabilities were intermediate $\left(\mathrm{h}^{2}=0.33-0.56\right)$ and broad-sense heritabilities were only slightly larger in most cases $\left(\mathrm{H}^{2}=0.36-0.61\right)$. Error variances were large for all color variables, witlo $\sigma_{\mathrm{e}}^{2}=37-55 \%$ of the phenotypic variance. The detection of large error variances suggests that more extensive sampling of individual genotypes or incorporation of family information into a selection index could improve the precision of selection for genotypes with superior fresh fruit color (Falconer, 1981). Because the genetic variance for color is mostly additive, clonal tests should be about as effective in choosing parents as family-index methods (Namkoong, 1979).

Means for all objective color variables differed significantly between locations (Table 4). Fruit collected at Winters was significantly darker (lower external and internal L), less saturated in external redness (lower external a), and more saturated in internal redness (higher internal a) than fruit obtained at Watsonville (Table 3). However, variance components due to locations were a large fraction of the phenotypic variance only for external and internal $\mathrm{L}(24 \%$ and $8 \%$, Table 5). The between-location differences detected for objective variables were not found for subjective scores. Subjective color perception depends on both color value and saturation; the differences detected for objective variables were apparently compensatory and had little effect on subjective perception of fruit color. Significant genetic $\times$ location interaction effects were detected only for external a (Table 4). Interaction variances were responsible for $0 \%$ to $12 \%$ of the phenotypic variance, and the sum of additive and dominant interaction components was never $>35 \%$ of the sum of the corresponding genetic components (Table 5), indicating consistency of relative color ratings between the two locations.

The relationships between objective and subjective color variables were evaluated to determine their relative usefulness in selecting genotypes with desirable color qualities. Multiple regressions with external or internal objective variables as predictors explained $69 \%$ and $59 \%$ of the phenotypic variance for their corresponding subjective scores. Because error variances were large, predictive values are expected to improve with more extensive sampling of fruit from individual genotypes. Genetic correlations between objective variables and their corresponding subjective scores were also significant and $\operatorname{larg}\left(\left|\mathbf{r}_{\mathbf{g}}\right|=0.82\right.$ - 1.00, Table 6), indicating that both criteria contain similar genetic information. Heritabilities and error components of variance were similar for objective and subjective variables (Table 5 ), indicating similar experimental precision. Because genetic

Table 3. Means and SD (in parentheses) for six strawberry fruit color variables determined for parents and offspring at two test locations. ${ }^{z}$

\begin{tabular}{|c|c|c|c|c|c|c|}
\hline & \multicolumn{3}{|c|}{ External color } & \multicolumn{3}{|c|}{ Internal color } \\
\hline & $\mathrm{L}$ & $a$ & Score & $\mathbf{L}$ & $\mathrm{a}$ & Score \\
\hline $\begin{array}{l}\text { Parents } \\
\text { Offspring }\end{array}$ & $\begin{array}{l}26.9(2.7) \\
27.9(3.6)\end{array}$ & $\begin{array}{l}32.2(4.1) \\
32.7(4.5)\end{array}$ & $\begin{array}{c}\text { Winters } \\
8.3(0.9) \\
8.2(0.8)\end{array}$ & $\begin{array}{l}47.7(5.5) \\
50.1(6.3)\end{array}$ & $\begin{array}{l}34.0(4.3) \\
31.5(6.5)\end{array}$ & $\begin{array}{l}4.9(1.4) \\
4.7(1.7)\end{array}$ \\
\hline $\begin{array}{l}\text { Parents } \\
\text { Offspring }\end{array}$ & $\begin{array}{l}29.6(1.8) \\
30.6(3.2)\end{array}$ & $\begin{array}{l}32.6(2.4) \\
34.0(4.6)\end{array}$ & $\begin{array}{c}\text { Watsonville } \\
8.2(0.9) \\
8.1(0.8)\end{array}$ & $\begin{array}{l}51.6(5.2) \\
52.8(6.4)\end{array}$ & $\begin{array}{l}33.0(4.5) \\
29.6(7.4)\end{array}$ & $\begin{array}{l}5.6(1.7) \\
4.9(1.7)\end{array}$ \\
\hline
\end{tabular}

${ }^{2}$ Hunter $\mathrm{L}$ and a; subjective score based on color chart. 
Table 4. Results of ANOVA for six strawberry fruit color variables obtained using factorial analyses of 20 biparental crosses.

\begin{tabular}{|c|c|c|c|c|c|c|}
\hline \multirow[b]{3}{*}{ Source } & \multicolumn{6}{|c|}{ Mean squares ${ }^{z}$} \\
\hline & \multicolumn{3}{|c|}{ External color } & \multicolumn{3}{|c|}{ Internal color } \\
\hline & $\mathrm{L}$ & $\mathrm{a}$ & Score & $\mathrm{L}$ & $\mathbf{a}$ & Score \\
\hline Location (L) & $1186.7^{* *}$ & $167.8^{*}$ & 0.4 & $1014.7^{* *}$ & $489.3^{*}$ & 4.1 \\
\hline Male (M) & $407.0^{* *}$ & $953.3^{* *}$ & $18.2^{* *}$ & $904.0^{* *}$ & $1083.0^{* *}$ & $65.1^{* *}$ \\
\hline Female (F) & 12.0 & 56.1 & 0.2 & $295.8^{*}$ & $361.0^{* *}$ & $24.6^{* *}$ \\
\hline$M \times F$ & 14.8 & $42.2^{* *}$ & $1.6^{* *}$ & 64.3 & 59.3 & 3.0 \\
\hline $\mathrm{L} \times \mathrm{M}$ & 9.7 & $37.8^{*}$ & 0.4 & 42.3 & 53.3 & 1.1 \\
\hline $\mathrm{L} \times \mathrm{F}$ & 19.0 & 11.7. & 0.1 & 13.2 & 15.2 & 1.5 \\
\hline $\mathrm{L} \times \mathrm{M} \times \mathrm{F}$ & 14.8 & 14.5 & 0.2 & 55.1 & 60.5 & 1.6 \\
\hline Residual & 9.6 & 14.8 & 0.5 & 33.4 & 41.2 & 2.4 \\
\hline
\end{tabular}

${ }^{2}$ Hunter $\mathrm{L}$ and a; subjective score based on color chart.

*,** Significant at $P=0.05$ and 0.01 , respectively.

Table 5. Components of variance expressed as percent of the phenotypic variance and heritabilities (with SE in parentheses) for six strawberry fruit color variables obtained from factorial ANOVA of 20 biparental crosses. ${ }^{z}$

\begin{tabular}{|c|c|c|c|c|c|c|}
\hline \multirow[b]{2}{*}{ Parameter } & \multicolumn{3}{|c|}{ External color } & \multicolumn{3}{|c|}{ Internal color } \\
\hline & $\mathrm{L}$ & $\mathrm{a}$ & Score & $\mathrm{L}$ & $a$ & Score \\
\hline$\overline{\sigma_{1}^{2}}$ & 24 & 2 & 0 & 8 & 3 & 0 \\
\hline$\sigma_{a}^{2}$ & 31 & 54 & 33 & 33 & 34 & 39 \\
\hline$\sigma_{d}^{2}$ & 0 & 6 & 20 & 3 & 0 & 6 \\
\hline$\sigma_{\mathrm{al}}^{2}$ & 0 & 1 & 0 & 0 & 0 & 0 \\
\hline$\sigma_{\mathrm{dl}}^{2}$ & $8:$ & 0 & 0 & 12 & 8 & 0 \\
\hline$\sigma_{e}^{2}$ & 37 & 37 & 47 & 44 & 55 & 55 \\
\hline $\mathrm{h}^{2}$ & $0.41(0.23)$ & $0.56(0.31)$ & $0.33(0.25)$ & $0.36(0.15)$ & $0.36(0.16)$ & $0.39(0.17)$ \\
\hline $\mathrm{H}^{2}$ & $0.41(0.24)$ & $0.61(0.33)$ & $0.53(0.27)$ & $0.39(0.17)$ & $0.36(0.17)$ & $0.45(0.18)$ \\
\hline
\end{tabular}

${ }^{2}$ Hunter $\mathrm{L}$ and a; subjective score based on color chart.

Table 6. Phenotypic correlations (above diagonal) and genetic correlations (below diagonal) for six strawberry fruit color variables obtained from multivariate factorial ANOVA of 20 biparental crosses. ${ }^{\mathrm{z}}$

\begin{tabular}{|c|c|c|c|c|c|c|}
\hline \multirow[t]{2}{*}{ r. } & \multicolumn{3}{|c|}{ External color } & \multicolumn{3}{|c|}{ Internal color } \\
\hline & $\mathrm{L}$ & $\mathrm{a}$ & Score & $\mathrm{L}$ & $\mathbf{a}$ & Score \\
\hline External L & -- & $0.61^{* *}$ & $-0.63^{* *}$ & $0.43^{* *}$ & $-0.26^{* *}$ & $-0.42^{* *}$ \\
\hline External a & $0.95^{* *}$ & --- & $-0.65^{* *}$ & $0.48^{* *}$ & $-0.25^{* *}$ & $-0.48^{* *}$ \\
\hline External score & $-0.99 * *$ & $-0.98^{* *}$ & --- & $-0.44^{* *}$ & $0.22^{* *}$ & $0.42^{* *}$ \\
\hline Internal L & 0.52 & 0.44 & $-0.65^{*}$ & --- & $-0.77^{* *}$ & $-0.67^{* *}$ \\
\hline Internal a & -0.01 & -0.09 & 0.18 & $-0.82^{* *}$ & --- & $0.56^{* *}$ \\
\hline Internal score & -0.49 & -0.62 & 0.60 & $-1.00^{* *}$ & $0.84^{* *}$ & --- \\
\hline
\end{tabular}

${ }^{2}$ Hunter $\mathrm{L}$ and a; subjective score based on color chart.

parameters for objective and subjective variables were similar in magnitude and precision, and because genetic correlations were large, indirect selection based on objective variables is expected to result in selection response similar to response from direct selection using subjective scores. However, objective procedures avoid problems of scorer bias and may be a superior alternative regardless of statistical considerations.

One caution regarding objective assessments is that Hunter L and a values may not be biologically or statistically independent (Francis, 1969), and the relationship between these variables may differ depending on experimental procedures. For example, phenotypic and genetic correlations between $\mathrm{L}$ and a values were significant for both internal and external color but differed in sign (Table 6). The genetic correlation between external $\mathrm{L}$ and a was positive $\left(\mathrm{r}_{\mathrm{g}}=0.95, P<0.01\right)$, indicating that dark fruit have low color saturation. Internal $\mathrm{L}$ and a were negatively correlated $\left(\mathrm{r}_{\mathrm{g}}=-0.82, P<0.01\right)$, indicating that color sat- uration is greater with darker fruit. Several factors that induce external fruit darkening (enzymatic browning, metal completing, copigmentation) can interfere with pigment detection (Gross, 1987; Harbourne, 1988). Fruit darkening may explain the negative correlation between external $\mathrm{L}$ and a but may be unimportant for freshly cut surfaces and be of little consequence for internal color. Also, interactions between fruit darkening and color detection may be responsible for the absence of detectable differences between internal and external a (Table 3 ).

With one exception (the $r_{g}$ between external subjective score and internal L), significant genetic correlations between variables that describe internal and external color were not detected (Table 6). The absence of significant genetic correlations suggests that external and internal color are conditioned largely by different sets of genes. Independent inheritance of internal and external color traits may result either from tissue-specific differences in the expression of genes that control the synthesis 
and distribution of pigments or from the interaction of pigments with factors that affect the expression of color. For example, the stability of anthocyanins and the expression of color for specific anthocyanin combinations due to copigmentation and metal completing depend on tissue chemistry (Harbourne, 1988). Regardless, evaluation of strawberry fruit color using juice or processed products may confound genetic and environmental factors that condition flesh and skin color separately, and may provide inappropriate criteria for selecting color traits in fresh fruit.

\section{Literature Cited}

Becker, W.A. 1984. Manual of quantitative genetics: fourth ed. Academic Enterprises, Pullman, Wash.

Comstock, R.E. and H.F. Robinson. 1948. The components of genetic variation in populations of bi-parental progenies and their use in estimating the average degree of dominance. Biometrics 4:254-266.

Comstock, R. E., T. Kelleher, and E.B. Morrow. 1958. Genetic variation in an asexual species, the garden strawberry. Genetics 43:634646.

Falconer, D.S. 1981. Introduction to quantitative genetics. Longman Press, New York.

Francis, F.J. 1969. Color measurement in plant breeding. HortScience 5:102-106.

Gross, J. 1987. Pigments in fruits. Academic, London.

Hallauer, A.R. and J.B. Miranda. 1981. Quantitative genetics in maize breeding. Iowa State Univ. Press, Ames.

Harbourne, J.B. 1988. The flavenoids: recent advances, p. 1056-1095. In: T.W. Goodwin (cd.). Plant pigments. Academic, San Diego, Calif.

Hoover, M.W. and R.A. Dennison. 1954. Some treatments influencing the quality of Florida frozen strawberries. Proc. Amer. Soc. Hort. Sci. 65:188-194.

Li, C. 1990. The residual effects of controlled atmospheres on postharvest physiology and quality of strawberries. MS Thesis, Univ. of Calif., Davis.
Li, C. and A.A. Kader. 1989. Residual effects of controlled atmospheres on postharvest physiology and quality of strawberries. J. Amer. Soc. Hort. Sci. 114:629-634.

Lundergan, C.A. and J.N. Moore. 1975. Inheritance of ascorbic acid content and color intensity in fruits of strawberry (Fragaria $\times$ ananassa Duch.). J. Amer. Soc. Hort. Sci. 100:633-635.

Morris, J. R., W.A. Sistrunk, C.A. Sims, G.L. Main, and E.J. Wehunt. 1985. Effects of cultivar, postharvest storage, preprocessing dip treatments, and stvle of pack on the processing quality of strawberries. J. Amer. Soc. Hort. Sci. 110: 172-177.

Namkoong, G. 1979. Introduction to quantitative genetics in forestry. U.S. Dept. Agr.-For. Serv. Tech. Bul. 1588.

Rosen, J.C. and A.A. Kader. 1989. Postharvest physiology and quality maintenance in sliced pear and strawberry fruit. J. Food Sci. 54:656659.

SAS Institute Inc. 1985. SAS users guide: Statistics. version 5.1983. SAS Institute, Inc., Cary, N.C.

Searle, S.R. 1971. Linear models. Wiley, New York.

Shaw, D.V., R.S. Bringhurst, and V. Voth. 1988. Quantitative genetic variation for resistance to leaf spot (Ramularia tulasnei) in California strawberries. J. Amer. Soc. Hort. Sci. 113:451-456.

Shaw, D.V. 1991. Recent advances in the genetics of strawberry. In: A. Dale and J.J. Luby (eds.). The strawberry into the 21 st century. Timber Press, Portland, Ore. (In press.)

Sistrunk, W.A. and J.R. Morris. 1985. Strawberry quality: influence of cultural and environmental factors. In: H.E. Pattee (cd.). Evaluation of quality of fruits and vegetables. AVI Publishing, Westport, Conn.

Voth, V. and R.S. Bringhurst. 1970. Influence of nursery harvest date, cold storage, and planting date on performance of winter planted California strawberries. J. Amer. Soc. Hort. Sci. 95:496-500.

Welch, N. 1989. Strawberry production in California. Univ. of California, Coop. Ext. Lflt. no. 2959.

Wrolstad, R. E., T.B. Putnam, and G.W. Varseveld. 1970. Color quality of frozen strawberries: effects of anthocyanins, $\mathrm{pH}$, total acidity and ascorbic acid variability. J. Food Sci. 35:448-452. 